\title{
Study on the Volatility of Public Opinion of Coal Mine Safety Incidents Based on GARCH Model
}

\author{
Fei Wang \\ School of Economics and Trade, Zhengzhou Institute of Technology, Zhengzhou, Henan, 450044 \\ Email: oscarpublic@126.com
}

Keywords: GARCH model; Coal mine safety; Public opinion; Volatility

\begin{abstract}
This paper conducts an empirical study on the volatility characteristic of public opinion evolution of coal mine safety incidents by using GARCH model. It finds that the volatility of public opinion evolution of coal mine safety incidents has cluster effect and ARCH effect. Hence, GARCH model and TARCH model are both applicable to the volatility analysis, while TARCH model is superior to GARCH model.
\end{abstract}

\section{Introduction}

The public opinion of coal mine safety incidents can also be defined as public concern about coal mine accidents, and its evolution has a very clear life cycle characteristic. [1] Meanwhile, the volatility also has cluster and asymmetry characteristics. Therefore, GARCH model can be adopted to depict the rule of volatility of public opinion of coal mine safety incidents, although in the vast majority of cases, GARCH is used in stock market analysis, like Sabiruzza-man, et al (2010), Liu, et al (2010), Jinlin Zhang \& Genqing He (2012), Chenhui Yang \& Xinmei Liu (2012).

\section{Data feature and stationary test}

\subsection{Statistical description of variable}

When there are coal mine safety incidents, the representative indexes for measuring public opinion evolution include the frequency of reports from all kinds of media such as TV, newspapers and network.[2] While in this paper, we choose Baidu search index of coal mine accidents as a substitutive indicator, which is represented by $S I_{t}$, the sample period is from January $1^{\text {st }}, 2011$ to May $16^{\text {th }}$, 2014, and all data are weekly average. Generally speaking, the change or evolution of public opinion has a typically periodical feature that can be divided into three stages including forming, developing and fading, so, with regard to coal mine safety incidents, they must also obey the rule with exception. [3] Besides, the evolution of public opinion toward emergencies usually has a cluster characteristic during the volatility, namely, it may fluctuate sharply or slightly for some time. [4] As for the reasons, it is because the public may increase their network click or search after an emergency due to their strong group psychology, and thus more concern may give rise to a new round of public opinion volatility. See Figure 1.

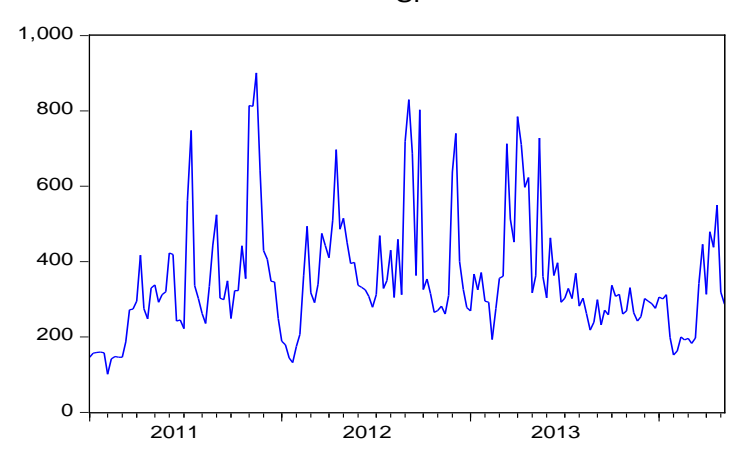

Fig. 1 Search index of coal mine accidents (2011.1-2014.5) 
Moreover, if exploring the change rate of search index which can be defined as $R S I_{t}=\ln \left(S I_{t} / S I_{t-1}\right)$, we can also come to the same conclusion. See Figure 2.

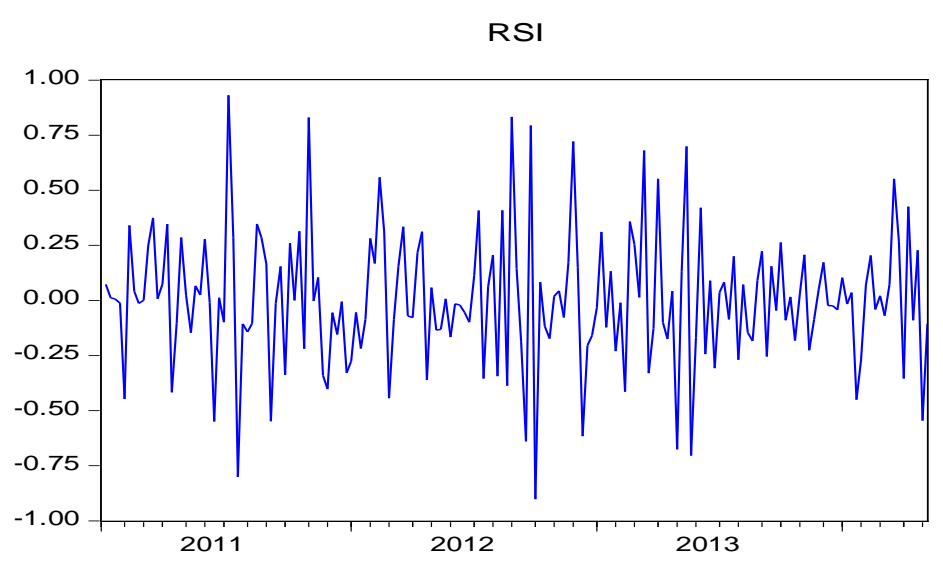

Fig. 2 The change rate of search index (2011.1-2014.5)

\subsection{ADF test}

In order to avoid spurious regression problem and make sure that time series data is stationary, ADF test is necessary. From Table 1, we can see that the ADF value is -6.236 , lower than the critical value of significance level at $1 \%$, and the corresponding p-value is 0.000 , this means the time series of search index represented by $S I_{t}$ is stationary.

Table 1 The ADF test of $\mathrm{SI}_{\mathrm{t}}$

\begin{tabular}{lccc}
\hline \multicolumn{2}{l}{ Null hypothesis: $\mathrm{SI}_{\mathrm{t}}$ has unit root } & & \\
\multicolumn{2}{l}{ Test type: $(\mathrm{c}, 0,0)$} & & \\
& & t-Statistic & P Value \\
ADF Value & & -6.236140 & 0.0000 \\
Critical Value & 1\% level & -3.467851 & \\
& 5\% level & -2.877919 & \\
& $10 \%$ level & -2.575581 & \\
\hline
\end{tabular}

\section{ARCH effect test}

When examining $S I_{t}$ partial correlation coefficient (PAC), the lag order is 1, so the lag order of auto regression model of coal mine accidents evolution is 1 . The regression result is as follows ( $t$ represents t-statistic):

$$
\begin{aligned}
S I_{t}= & 129.297+0.637 S I_{t-1}+e_{t} \\
& (5.728) \quad(10.963) \\
R^{2}= & 0.4099, \text { Log likelihood }=-1087.867, \text { AIC }=12.45, S C=12.492
\end{aligned}
$$

The regressive parameters are significant, when conducting ARCH LM test, the result shows that $\mathrm{p}$ value is 0.0036, which means there is ARCH effect in this model. Hence, GARCH model is applicable to the volatility analysis of public opinion of coal mine safety incidents.

In $\operatorname{GARCH}(q, p)$ model, we assume that the mean equation is an autoregression model with random walk, while the lag order of ARCH item and GARCH item in conditional variance equation can be determined by comparison of different models. According to AIC and SC standard and parameter significance, $\operatorname{GARCH}(1,1)$ is considered to be the best model among all other kinds of models like $\operatorname{GARCH}(1,2)$ 、 $\operatorname{GARCH}(2,1) \operatorname{GARCH}(2,2)$. The regression result is as follow: 


$$
\begin{aligned}
S I_{t}= & 65.867+0.791 S I_{t-1}+\hat{u}_{t} \\
& (3.056) \quad(12.418) \\
\hat{\sigma}_{t}^{2}= & 740.213+0.214 \hat{u}_{t-1}^{2}+0.780 \hat{\sigma}_{t-1}^{2} \\
& (1.990) \quad(3.908) \quad(19.779) \\
R^{2}= & 0.3879, \text { Loglikelihood }=-1073.63, \text { AIC }=12.335, S C=12.440
\end{aligned}
$$

Equation (2) has a lower AIC and SC compared with Equation (1), and all parameters in its conditional variance equation are positive and significant, this means $\operatorname{GARCH}(1,1)$ is a better choice for simulating the volatility of search index of coal mine accidents, see Figure 3 . It is easy to find that $\operatorname{GARCH}(1,1)$ can successfully simulate every sudden change of search index, and can describe the intensity of sudden change precisely. Hence, $\operatorname{GARCH}(1,1)$ is able to depict the rule of volatility of public opinion of coal mine safety incidents and can provide preliminary information as an early warning.

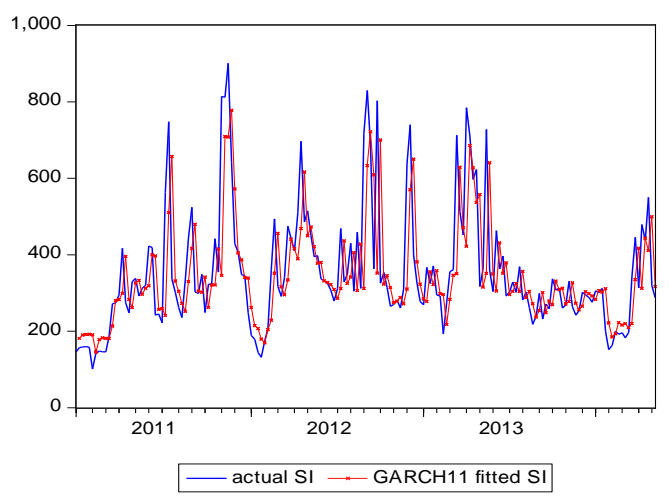

Fig. 3 Simulation of Volatility of Public Opinion in $\operatorname{GARCH}(1,1)$

Besides, GARCH(1,1) model has no conditional heteroscedasticity, when conducting ARCH LM test, the result shows that p value is 0.8286 , which means no ARCH effect can be found, and all the other tests including AC and PAC support this conclusion.

\section{Asymmetry effect test}

In capital market, the change of financial asset price usually has such a phenomenon, namely, good news and bad news have different influences on financial asset price, and this is so-called asymmetry effect or leverage effect. When studying volatility of public opinion, this effect also exists. Hence, TARCH model can be applied to test this effect.

\subsection{TARCH model estimation}

Usually, the conditional variance equation of TARCH model is as follows:

$$
\sigma_{t}^{2}=\omega+\sum_{i=1}^{p} \alpha_{i} u_{t-i}^{2}+\sum_{j=1}^{q} \beta_{j} \sigma_{t-j}^{2}+\sum_{k=1}^{r} \gamma_{k} u_{t-k}^{2} d_{t-k}
$$

Among which, $d_{t-k}$ is dummy variable, when $u_{t-k}<0$ (namely bad news), $d_{t-k}=1$, when $u_{t-k}>0$ (namely good news), $d_{t-k}=0$. If $\gamma_{k} \neq 0$, there is an asymmetry effect, and if $\gamma_{k}<0$, the effect may narrow the volatility, if $\gamma_{k}>0$, the effect may enlarge the volatility.

When taking 1 and 2 as threshold values respectively, we can find that $\operatorname{TARCH}(1,1)$ is superior to $\operatorname{TARCH}(2,1)$ based on AIC and SC standard. So, we use $\operatorname{TARCH}(1,1)$ to test the asymmetry effect, and its estimation result is as follows: 


$$
\begin{aligned}
S I_{t}= & 67.542+0.803 S I_{t-1}+\hat{u}_{t} \\
& (2.629) \quad(10.352) \\
\hat{\sigma}_{t}^{2}= & 1699.893+0.408 \hat{u}_{t-1}^{2}-0.393 \hat{u}_{t-1}^{2} d_{t-1}+0.688 \hat{\sigma}_{t-1}^{2} \\
& (0.0001) \quad(2.975) \quad(-2.004) \quad(12.935) \\
R^{2}= & 0.3818, \text { Loglikelihood }=-1074.805, \text { AIC }=12.352, \text { SC }=12.461
\end{aligned}
$$

In equation (4), the coefficient of asymmetry effect item is -0.393 , which is very significant, this means there is asymmetry effect in the volatility of search index. For coal mine accidents, the definition of news nature is a little bit different from general capital market, because coal mine accidents are bad news and may give rise to public concern, while the search index may increase in response. Thus, in our TARCH model, good news can be defined as $u_{t-1}<0$ and $d_{t-1}=1$. On the contrary, bad news can be defined as $u_{t-1}>0$ and $d_{t-1}=0$. Our model shows that good news has an influence of 0.015 on the volatility of search index of coal mine accidents, while bad news's influence is 0.408 .

\subsection{TARCH model fitting effect}

Figure 4 shows the fitting effect of TARCH model and GARCH model, it is clear that TARCH is superior to GARCH no matter in shape simulation or deviation degree.

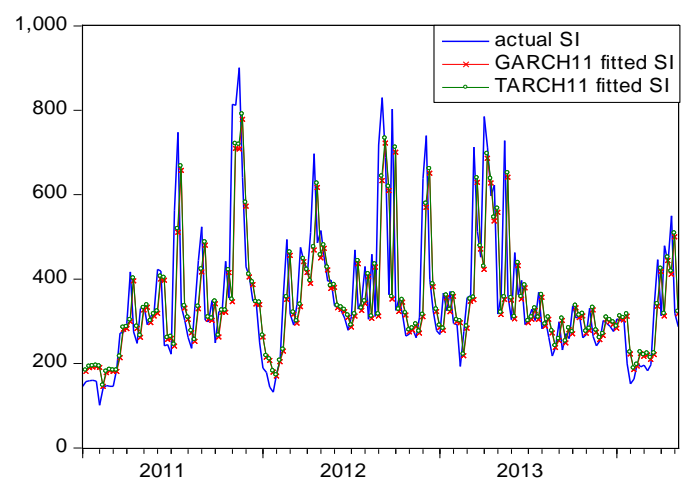

Fig. 4 The fitting effect of TARCH and GARCH

In addition, when conducting ARCH LM test, AC test and PAC test, all evidences support that the residual sequence of TARCH(1,1) has no conditional heteroscedasticity.

\section{Conclusions}

This paper conducts an empirical study on the volatility characteristic of public opinion evolution of coal mine safety incidents by using GARCH model, based on weekly average data analysis of Baidu search index of coal mine accidents from January $1^{\text {st }}, 2011$ to May $16^{\text {th }}, 2014$, the conclusion can be summarized as follows:

First, the volatility of public opinion evolution of coal mine safety incidents has cluster effect in the statistical sense.

Second, GARCH model is applicable to the volatility analysis. The evolution of public opinion has a typical autoregression feature, so it is appropriate to set first-order autoregression random walk model based on search index, and when conducting ARCH effect test on residual, it shows that there is ARCH effect. Hence, GARCH model is available for in-depth research.

Third, TARCH has an advantage over GARCH when describing the volatility of public opinion. Results show that both $\operatorname{GARCH}(1,1)$ and $\operatorname{TARCH}(1,1)$ are satisfactory, and they do not have conditional heteroscedasticity. Comparatively speaking, $\operatorname{TARCH}(1,1)$ is superior to $\operatorname{GARCH}(1,1)$ because TARCH $(1,1)$ can take good news and bad news into account, which can prove that good news is able to reduce the volatility of public opinion evolution of coal mine safety incidents. 


\section{Acknowledgements}

This work is supported by 2015 National Natural Science Foundation Project "Prevention, control and guidance of unsafe emotion of employees in high-risk Industries_—An empirical study of emotional event, emotional bearing and motional load management” (No. 71573086).

\section{References}

[1] Zakoian, J. M. Threshold Heteroskedastic Models[J]. Journal of Economic Dynamics and Control, 1994, (18): 931-955.

[2] Basel, M.A., Valentina Corradi. Predicting the Volatility of the S\&P -500 Stock Index via GARCH Models: The Role of Asymmetries[J]. International Journal of Forecasting, 2005, (1): 167-183.

[3] Md. Sabiruzza-man, etc. Modeling and Forecasting Trading Volume Index: GARCH versus TGARCH Approach[J]. The Quarterly Review of Economics and Finance, 2010, (2): 141-145.

[4] Liu, Hung-Chun, Hung Jui-Cheng. Forecasting S\&P-100 Stock Index Volatility: The Role of Volatility Asymmetry and Distributional Assumption in GARCH Models [J]. Expert Systems with Applications, 2010, (7): 4928-4934. 